\title{
Transposition
}

Musique et Sciences Sociales

9| 2021

Musique et sexualité

\section{L'hyperféminisation des chanteuses japonaises : shôjo kashu et aidoru}

Hyperfeminization of female singers in Japan: shôjo kashu and aidoru

Chiharu Chûjô et Clara Wartelle-Sakamoto

\section{OpenEdition}

1 Journals

Édition électronique

URL : http://journals.openedition.org/transposition/5910

DOI : 10.4000/transposition.5910

ISSN : 2110-6134

Éditeur

CRAL - Centre de recherche sur les arts et le langage

Référence électronique

Chiharu Chûjô et Clara Wartelle-Sakamoto, «L'hyperféminisation des chanteuses japonaises : shôjo kashu et aidoru », Transposition [En ligne], 9|2021, mis en ligne le 01 mars 2021, consulté le 23 avril 2021. URL : http://journals.openedition.org/transposition/5910; DOI : https://doi.org/10.4000/ transposition. 5910

Ce document a été généré automatiquement le 23 avril 2021.

La revue Transposition est mise à disposition selon les termes de la Licence Creative Commons Attribution - Partage dans les Mêmes Conditions 4.0 International. 


\title{
L'hyperféminisation des chanteuses japonaises : shôjo kashu et aidoru
}

Hyperfeminization of female singers in Japan: shôjo kashu and aidoru

\author{
Chiharu Chûjô et Clara Wartelle-Sakamoto
}

\section{NOTE DE L'AUTEUR}

Notes sur la translittération

Les mots japonais sont transcrits dans le système Hepburn modifié :

e se prononce [e] (fermé)

$\mathrm{u}$ se prononce $[\mathrm{u}]$

$\mathrm{g}$ se prononce $[\mathrm{g}]$

les syllabes commençant par h correspondent à une voyelle aspirée

le $r$ est proche $d u$ « 1 » français

les voyelles longues sont rendues par un accent circonflexe, ex : Tôkyô

la nasale est rendue par un $\mathrm{n}$

les consonnes géminées sont indiquées en doublant la consonne, ex : gakkô

le point en milieu de mot après un « $\mathrm{n}$ » est utilisé pour marquer la limite entre deux syllabes, ex : min.yô

Pour les noms japonais, le patronyme précède toujours le prénom, conformément à l'usage local.

\section{Introduction}

1 Il est une catégorie d'artistes spécifique au monde de la musique populaire japonaise : celle des aidoru ${ }^{1}$. Le terme aidoru, du français «idole», a émergé au Japon avec le film franco-italien Cherchez l'idole ${ }^{2}$, sorti dans les cinémas de l'archipel en $1964^{3}$. L'industrie musicale japonaise l'a souvent utilisé sans saisir le sens exact du terme. Les vedettes japonaises étaient indifféremment appelées soit aidoru, soit sutâ (de l'anglais «star»), 
indiquant par là qu'il s'agissait de célébrités ${ }^{4}$. Désignant aujourd'hui des adolescentes vêtues de tenues extrêmement féminisées et offertes aux yeux de spectateurs principalement masculins, les aidoru ne semblent guère s'interroger sur leur représentation outrancière d'un genre hypernormé, et proposent à leurs fans masculins en échec social ou professionnel un certain lieu de " réconfort ». Cette norme sociale régissant les représentations de la féminité se répercute sur la posture de bien des chanteuses: elles s'incarnent soit dans l'immaturité naïve renvoyant à la vulnérabilité, soit dans une certaine magnanimité fondée sur la maternité.

2 Ce phénomène, que l'on peut associer à la place de la femme dans la société japonaise contemporaine $e^{5}$, s'inscrit en réalité dans un processus bien plus ancien, initié par le succès des shôjo kashu, les enfants chanteuses du début du $\mathrm{xx}^{\mathrm{e}}$ siècle. Ces fillettes, qui interprétaient un répertoire composé exclusivement de chansons pour enfants, s'adressaient à un public d'adultes nostalgiques qui projetaient sur elles une vision fantasmée de l'enfance pure et naïve. Véritables coqueluches de la foule, elles multipliaient les apparitions à la radio et dans les journaux, à l'instar des aidoru d'aujourd'hui. Comme ces dernières, leur carrière était brève : passé l'âge de douze ans, elles devaient renoncer à poursuivre leur activité de chanteuse, ayant déjà perdu la fraîcheur juvénile qui constituait l'attente principale du public.

3 Cette tendance dura jusque dans les années 1950 où s'amorça une transformation de cette attente, en raison des changements socioculturels provoqués en particulier par l'occupation américaine. D'une part, la défaite et les traumatismes de la guerre marquèrent la production musicale de l'époque: les chansons jugées nationalistes furent censurées, y compris dans le répertoire de chants pour enfants d'où furent évincées toutes les pièces à tendance nationaliste, militariste ou en lien avec le shintoïsme. D'autre part, le rôle des vedettes fut davantage soumis au processus de starification de l'industrie capitaliste américaine et aux effets médiatiques de la télévision qui s'imposa peu à peu dans les ménages après-guerre. La transformation des répertoires, l'évolution de la conceptualisation des vedettes, la démocratisation d'un nouveau type d'écran constituent ainsi les éléments au fondement de la représentation hyperféminisée des chanteuses japonaises d'aujourd'hui. On constate dès lors, chez des artistes comme Misora Hibari, un transfert de la figure de l'enfant star à celle de la femme-enfant. Celle-ci eut aussi un rôle majeur dans le passage de l'économie de la star à celle de l'aidoru. Si les droits des artistes femmes furent peu à peu démocratisés dans la sphère musicale, les jeunes chanteuses adoptèrent un nouveau rôle dans des mises en scène de séduction implicite qui provoqua une transformation des répertoires interprétés.

4 Dans cet article, nous proposons de revenir sur l'histoire de la figure de l'aidoru dans l'industrie musicale japonaise, en remontant au phénomène des shôjo kashu afin de mieux saisir le rapport constaté entre l'évolution de la production musicale et la sexualité représentée dans l'imaginaire que ces chanteuses incarnent. 


\section{De l'origine des aidoru : le succès avant-guerre des shôjo kashu}

\section{Le « mouvement des chants pour enfants » à partir des années 1920}

5 Le répertoire des chants pour enfants s'est développé à partir du dernier tiers du XIX $x^{e}$ siècle, suite à l'introduction de l'éducation musicale dans le programme scolaire du système éducatif moderne. Cet enseignement, intitulé shôka («chants scolaires») prenait la forme d'une pratique vocale hebdomadaire qui devint obligatoire en 1907 pour tous les enfants du primaire. Le répertoire de shôka, élaboré sur le modèle des manuels de chant américains, contribua à diffuser au sein de la population la musique tonale et métrique d'origine européenne ${ }^{6}$ et la pratique du chant en chorale. Cependant, l'éducation musicale prodiguée par le biais de ces shôka fut fortement critiquée dès le début du $\mathrm{xx}^{\mathrm{e}}$ siècle. En effet, les textes de ces chants, extraits des classiques de littérature japonaise ou à portée morale, demeuraient pour la plupart incompris des enfants et n'étaient destinés qu'à être des auxiliaires à l'instruction, et non à développer l'écoute et le goût musical des enfants. Par ailleurs, grâce à la diffusion de nouvelles idées pédagogiques (en particulier celles de Paul Natorp, Friedrich Fröbel et John Dewey, développées dès les années 1910) et en conséquence d'une abondante production de littérature de jeunesse, la place de l'enfant dans la société fit l'objet de réflexions et de débats, entraînant un intérêt grandissant vis-à-vis du folklore enfantin autochtone ${ }^{7}$. C'est dans cet engouement général pour la culture de l'enfance que naquit le dôyô undô, le «mouvement des chants pour enfants", dans les années 1920. Ce mouvement des chants pour enfants s'exprima notamment au travers des revues de littérature de jeunesse, à l'instar d'Akai tori («l'Oiseau rouge »), fondée par l'écrivain Suzuki Miekichi. Ce dernier avait pour ambition de créer un nouveau répertoire de "chants artistiques pour enfants » qu'il baptisa dôyô. Il réunit autour de son projet des écrivains, des poètes et des musiciens qui contribuèrent à son entreprise en publiant dans les pages de la revue des dôyô. De la pensée de Suzuki Miekichi découle le manifeste d'Akai tori, paru dans le numéro de juillet 1918 :

La majeure partie des lectures enfantines en vogue sont, pour de nombreuses raisons, de très mauvaise qualité, ainsi qu'on peut le constater à la vue de leurs couvertures vulgaires. L'idée que ces lectures puissent nuire à la pureté des enfants est terrifiante.

Contrairement aux Occidentaux, nous Japonais n'avons aucun artiste qui se soit consacré à la création de belles lectures destinées aux enfants.

La revue Akai Tori rejette les lectures enfantines de mauvaise qualité et est la pionnière d'un mouvement sans précédent qui vise à préserver et à développer la pureté des enfants, grâce aux sincères efforts réunis par des artistes de premier rang et menant à la constitution d'un groupe d'écrivains pour la jeunesse ${ }^{8}$.

Ce manifeste révèle le souci de concevoir des lectures de qualité sur le modèle de ce que Suzuki Miekichi avait pu constater en Occident ${ }^{9}$. Si, jusqu'alors, le procédé compositionnel adopté par les auteurs de chants scolaires consistait en un simple pastiche des pièces étrangères, les musiciens du mouvement des chants pour enfants s'appliquèrent à étudier plus scrupuleusement les comptines et la culture enfantine autochtones, dégageant peu à peu des spécificités musicales qu'ils cherchèrent à réemployer dans leurs créations. Si certaines tentatives sont considérées comme maladroites par certains musicologues ${ }^{10}$, cette démarche permit d'approfondir la 
connaissance d'un répertoire jusque-là écarté et de valoriser le caractère artistique de ce dernier. L'usage de publier des chansons s'étendit à d'autres revues de littérature enfantine de l'époque, entraînant la fixation du terme dôyô pour désigner ces pièces vocales.

\section{La théorie de «l'enfant pur»}

7 C'est une certaine vision de l'enfant que partageaient les membres du mouvement des chants pour enfants. Suzuki et ses pairs soutenaient en effet l'idée du caractère " pur ", intrinsèque à la nature même de l'enfant, qui lui permettait d'observer et de ressentir son environnement avec une innocence non altérée par des réflexions ou des comportements d'adultes. Le besoin de retrouver, en étant adulte, cette « pureté » peut être interprété de différentes manières. D'une part, il évoque le fantasme de la singularité et de l'authenticité de la culture japonaise avant sa confrontation à l'Occident. Kitahara Hakushû, poète de dôyô ayant mené une vaste entreprise de collecte de comptines japonaises dans tout l'archipel, affirmait ainsi qu'il fallait s'inspirer de l'innocence et de la spontanéité de création des enfants. En valorisant ces qualités et en prêtant aux dôyô le potentiel de développer celles-ci, les partisans du mouvement des chants pour enfants s'attribuaient la faculté de comprendre et de reproduire le folklore enfantin, sur fond de patriotisme. Ces discours identitaires empreints de nationalisme culturel se référaient alors à un ensemble d'éléments "proto-nationaux» et "pré-modernes» qui servirent à justifier la qualité du répertoire hybride qu'ils concevaient, et que l'on peut considérer comme une tradition inventé $e^{11}$. D'autre part, ce caractère immaculé de la représentation de l'enfance était présenté comme universel et asexué. Hormis quelques chansons qui pouvaient être adressées aux petites filles ou aux petits garçons en raison des thématiques qu'elles abordaient, les dôyô devaient concerner indifféremment l'ensemble des enfants ${ }^{12}$. Cette construction de l'innocence enfantine peut être comprise comme une réaction face à une transformation rapide de la société et de la famille, comme cela a été étudié par Anne Higonnet dans les cultures occidentales ${ }^{13}$, mais également comme une tentative d'asseoir la légitimité d'une culture enfantine japonaise dans un Japon de plus en plus moderne et occidentalisé.

8 Ainsi, alors que ce mouvement prétendait s'inspirer des comptines populaires auxquelles il empruntait des éléments langagiers et métrico-mélodiques, sa portée était avant tout artistique et destinée à préserver la " pureté » de l'enfant. Or, les comptines populaires décrivent bien souvent une réalité sociale peu heureuse : la pauvreté, la mort, le vol, ainsi que les vices humains, qui étaient autant de thèmes rejetés par les auteurs de dôyô. Le folklore enfantin regorge également de chansons grivoises ou tournant en dérision les personnages de son univers, parfois de façon très cruelle. La dimension transgressive (le détournement de chansons d'adultes par exemple) entrait en conflit avec la vision épurée de l'enfance du mouvement. Par ailleurs, ce dernier ignorait une autre réalité : celle du travail des enfants. Au début du siècle, la plupart des enfants aidaient très tôt aux tâches ménagères et aux travaux des champs ${ }^{14}$. Ces chansons pour enfants et chantées par des enfants sont paradoxalement rares dans la production de dôyô. La réticence à les prendre comme modèle de création peut s'expliquer par le lectorat des revues telles que Akai tori, qui s'adressaient à des enfants des classes sociales les plus aisées. «L'enfant pur ", dont le mouvement des chants pour enfants entendait s'inspirer, était en réalité une construction faite d'antinomies, celle 
d'un être dépossédé de personnalité, de caractères sexuels et de toute activité assimilée à la vie adulte. Cette vision fut encore renforcée dans les années suivantes avec l'apparition puis la médiatisation des enfants chanteurs.

\section{Les enfants stars d'une industrie musicale en plein développement}

\section{Les chorales d'enfants et les premiers enregistrements}

9 Au début du $\mathrm{Xx}^{\mathrm{e}}$ siècle, les enfants japonais avaient à leur disposition un répertoire de chansons de natures variées: chants scolaires, dôyô et comptines. Les pièces de ce répertoire étaient chantées par les enfants eux-mêmes dans la sphère privée et familiale, ou à l'école si leur succès les faisait intégrer les manuels scolaires, parfois aussi en public grâce, notamment, à la naissance des premiers chœurs d'enfants. La société Akai tori avait ainsi fondé sa propre chorale d'enfants en raison du succès rencontré par les chants inédits publiés dans la revue du même nom. Composée de petites filles, la chorale se produisit lors de divers concerts, interprétant les chants les plus populaires de l'époque. Dans les années 1930, on peut observer un certain engouement pour ces formations vocales qui étaient mixtes la plupart du temps. En 1933, le compositeur Kainuma Minoru fonda la chorale Otowa yurikagokai et, en 1943, Minagawa Kazuko rassembla des enfants qui allaient constituer la première génération de la chorale Hibari jidô gasshôdan. Ces deux chorales, toujours actives aujourd'hui, se professionnalisèrent peu à peu en étant diffusées à la radio et en participant à des concours de chant amateur ${ }^{15}$ organisés par les stations de radio et de télévision japonaises. Parmi les jeunes membres, plusieurs connurent une carrière musicale importante. Ces chorales contribuèrent grandement à diffuser les chants pour enfants japonais et étrangers dont elles réalisèrent de nombreux enregistrements.

10 La naissance de ces chorales marqua aussi le début du phénomène des chants pour enfants enregistrés, appelés rekôdo dôyô. En effet, alors que les années 1920 connaissaient une phonophilie grandissante, les musiciens japonais s'emparèrent de cette avancée technologique, l'enregistrement de leurs compositions sur des disques permettant en effet une meilleure promotion de leurs activités musicales. Les "tubes ${ }^{16}$ » qui naquirent de cette révolution eurent désormais une portée nationale, plus à même de toucher un public large qui puisse s'identifier à la musique qu'il écoutait, et qui s'apparentait davantage à une "musique de masse", opposée à la portée élitiste et idéaliste des dôyô pensés par le mouvement des chants pour enfants.

\section{Les premières interprètes féminines}

11 Peu à peu, la démocratisation des enregistrements discographiques permit l'émergence d'interprètes dont la représentation sur la scène publique prit une importance au moins égale à celles de l'auteur et du compositeur des chants pour enfants. En 1925, la NHK diffusa pour la première fois une jeune chanteuse, Murayama Hisako, âgée de 13 ans à l'époque. Elle chanta des pièces des compositeurs Komatsu Kôsuke, Hirota Ryûtarô et Kusakawa Shin, tous auteurs de dôyô. Les critiques musicaux s'intéressaient désormais autant à l'interprétation et à la technique vocale du chanteur qu'aux paroles et aux mélodies des pièces enregistrées. Ces jeunes chanteurs se 
formaient généralement au sein des chœurs d'enfants. Les plus talentueux étaient sélectionnés en tant que solistes et interprétaient les chansons destinées à être enregistrées. L'engouement suscité par ces jeunes interprètes entraîna l'apparition dans les années 1940-1950 des termes dôyô kashu (« enfant chanteur ") et shôjo kashu ( fillette chanteuse ») pour désigner ces vedettes juvéniles dont le répertoire était exclusivement constitué de chants pour enfants et de comptines. Majoritairement de sexe féminin, les dôyô kashu bénéficièrent d'une médiatisation importante notamment grâce à leurs apparitions radiophoniques et dans la presse. Bien que les garçons ne soient pas absents parmi ces jeunes vedettes, ils semblent moins nombreux et moins médiatisés que leurs homologues féminins. En effet, les shôjo kashu avaient l'exclusivité de figurer dans les revues d'avant-guerre consacrées aux jeunes filles ${ }^{17}$ qui en faisaient leurs têtes d'affiche aux côtés d'autres enfants chanteurs et acteurs de renommée internationale, à l'instar de Shirley Temple. Le phénomène des dôyô kashu fait ainsi écho à celui des enfants stars d'Hollywood des années 1920 et 1930. Ils partagent avec ces derniers de nombreux points communs, en particulier le fait de représenter tous les «bons" attributs de l'enfance, tels que l'innocence ou la sagesse innée, tout en se situant au-delà de la normalité de leurs pairs ${ }^{18}$, contribuant à entretenir l'engouement de la population pour ces jeunes prodiges. Dans le cadre de cet article, qui vise à étudier la question de l'hyperféminisation des chanteuses japonaises, nous nous concentrerons sur les shôjo kashu.

12 Dans la plupart des cas, ces jeunes artistes établissaient un contrat d'exclusivité avec les nouvelles maisons de disques qui virent le jour au début de l'ère Shôwa (1926-1989) : Nippon Columbia, Victor, Polydor Records et King Records, notamment. Il arrivait aussi qu'ils se consacrent à l'interprétation des œuvres d'un compositeur en particulier dont ils devenaient alors les représentants sur la scène publique. Déjà dans les années 1920, Motoori Nagayo, compositeur ayant publié un grand nombre de dôyô dans la revue pour la jeunesse Kin no fune, avait souhaité que l'enregistrement de ses pièces soit fait par des enfants. Comme d'autres partisans du mouvement des chants pour enfants, il demeurait convaincu que le plus talentueux des chanteurs adultes ne pouvait parvenir à émouvoir le public comme le ferait un enfant. Ainsi, il mit sur le devant de la scène ses trois filles, Midori, Kimiko et Wakaba, qui donnèrent des concerts dans tout le Japon et participèrent ainsi à la diffusion de ses œuvres. Kawamura Junko vit également sa carrière de chanteuse commencer grâce à l'interprétation des chansons de son père, le compositeur Kawamura Kôyô. Elle fit ses débuts chez Polydor Records en 1932 avec qui elle signa un contrat en 1935 avant d'enregistrer sous le label King Records à partir de 1936. La chanson Ureshii hinamatsuri, («Une joyeuse fête des filles», paroles: Satô Hachirô, musique : Kawamura Kôyô) rencontra un grand succès au moment de sa sortie en 1936.

13 Ce phénomène se renforça pour atteindre son apogée dans les années 1940-1950, avec de célèbres shôjo kashu telles que Kawada Masako, Koga Satoko, les sœurs Yasuda Sachiko et Akiko, Ban Kumiko, Kobato Kurumi, parmi bien d'autres, qui parvinrent à donner de la valeur à des chansons pour enfants. Mais comment expliquer l'ampleur du phénomène de starification des enfants chanteuses? Et quels sont les aspects qui laissent supposer que se trouvait déjà, chez les shôjo kashu, une forme de sexualisation implicite qui se révélera plus tard avec l'émergence de l'aidoru? 


\section{La construction de l'image ambivalente de la shôjo}

14 Le concept de shôjo, que l'on trouve dans le terme shôjo kashu, désigne une fillette ou une adolescente âgée de moins de 12 ou 13 ans. Ce terme a d'abord été véhiculé dans les années 1900 par la presse qui ciblait un lectorat féminin ${ }^{19}$. Ce qui fut d'abord une conséquence de la scolarisation de plus en plus généralisée des filles entraîna une réévaluation de la place de ces dernières dans la société. La loi sur l'enseignement secondaire pour les filles de $1899^{20}$ déterminait les devoirs qui leur incombaient en établissant notamment le principe du ryôsaikenbo ( «bonne épouse et mère avisée »), lequel dictait les objectifs exclusifs aux filles dans leur éducation, jusqu'à aboutir à une définition de ce qu'était la shôjo. Peu à peu, la représentation de cette entité fut précisée et fixée dans la culture populaire, la littérature, la publicité et le monde du spectacle. C'est ainsi que dans des magazines comme Shôjo sekai, publié à partir de 1906 aux éditions Hakubunkan, la fillette japonaise " devait faire en sorte de devenir adorable », et était soutenue l'idée qu'elle était avant tout «mignonne, gentille et docile ${ }^{21} »$. Ces qualités n'avaient d'autre finalité que de permettre d'assurer leur avenir, c'est-à-dire de trouver un mari, et de les faire correspondre à l'idéal d'épouse et de mère que glorifiait la société. Paradoxalement, en étant mise dans la position de celle qui devait plaire aux yeux masculins (et être choisie par eux), la fillette s'éloignait de la simplicité et de la discrétion prônées par la moralité rigide inculquée dans les écoles pour adopter une attitude plus coquette. Si, jusque dans la première moitié des années 1910, les représentations féminines dans les illustrations et les frontispices des magazines pour enfants étaient plutôt celles des adultes, on constate une augmentation de la présence de petites filles à partir de l'ère Taishô (1912-1926).

Dans les années 1920, cette image évolue encore avec notamment des artistes comme Fukiya Kôji (1898-1979) qui offre des représentations modernes, colorées et occidentalisées, mais également plus érotisées, des jeunes filles, dont l'influence s'exerça jusque dans les illustrations des magazines jeunesse féminins. Cependant, dans la décennie suivante, on constate un retour à la représentation introvertie et candide de la fillette, avec en particulier les œuvres de Nakahara Jun.ichi dont les personnages féminins sont dessinés avec de grands yeux naïfs et des silhouettes élancées ${ }^{22}$, correspondant au portrait de l'idéal féminin à la fois candide et charmant. Ces variations de la représentation de la fillette trouvent leur explication dans les mutations sociales de l'époque. D'une part, l'accès aux études des jeunes filles augmentant, le contrôle exercé sur ces dernières a pu dans une certaine mesure avoir été moins strict que dans les années 1900. Par ailleurs, l'intensification de la concurrence entre les revues et les magazines poussa ces derniers à se démarquer par l'image, optant pour des illustrations qui cherchaient à représenter au mieux le modernisme de l'époque. Les mouvements féministes, en particulier dans le milieu littéraire avec la revue Seitô («Bas bleu ») créée par des femmes et publiée entre 1911 et $1916^{23}$, ou encore la figure de la modan gâru ou moga ( femme moderne »), sorte de garçonne à l'apparence émancipée et vêtue de tenues occidentales, ont exercé une influence certaine jusque dans la production destinée aux jeunes filles. Enfin, la Grande Dépression des années 1930 et la montée de l'ultranationalisme japonais imposèrent de nouveau une vision traditionnelle et conservatrice de la femme au sein de la société ${ }^{24}$.

16 Dans tous les cas, la description des relations entre garçons et filles demeurait proscrite dans la presse et la littérature de jeunesse, ce qui entraîna l'apparition de 
subterfuges pour narrer les romances imaginées par les jeunes filles. Le succès du Takarazuka ${ }^{25}$ et l'engouement médiatique autour de ses stars contribuèrent par exemple à diffuser une forme d'éducation sentimentale "saine " auprès d'elles. En quelques décennies, la représentation féminine médiatisée auprès des jeunes filles montrait un comportement oscillant qui affectait l'innocence et la pudeur tout en présentant une tendance plus ou moins prononcée à la sensualitée ${ }^{26}$.

17 C'est dans un tel contexte que se développa le phénomène des shôjo kashu. Ces dernières avaient bien sûr comme public les enfants, dont elles interprétaient le répertoire de chansons, mais également les adultes. Ainsi, leur attitude en public et la mise en scène dont elles faisaient l'objet étaient orientées afin qu'elles correspondent à l'image que l'on avait alors de la figure de l'enfant. Cela entraîna une catégorisation de ces modèles d'adolescentes appuyée par le contexte socio-éducatif de l'époque. Tout était mis en œuvre pour qu'elles correspondent au fantasme de «l'enfant pur» de la vision du "mouvement des chants pour enfants » et de celui de shôjo de la culture populaire. Les enregistrements révèlent qu'elles chantaient en voix de poitrine afin, là encore, d'offrir une interprétation naturelle du répertoire abordé, alors même que plusieurs d'entre elles suivaient une formation rigoureuse à l'École de musique de Tôkyô. Il faut dire que les enfants chanteurs de l'ère Taishô et du premier tiers de l'ère Shôwa (jusqu'en 1950) ne chantaient en public que les répertoires qui leur étaient destinés, c'est-à-dire soit les chants scolaires, soit les dôyô. Cependant, une fois l'adolescence atteinte et à cause de la mue de la voix provoquée par la puberté, les fillettes ne pouvaient plus exercer leur activité en tant que shôjo kashu. Il arrivait que l'arrêt de leur activité soit publiquement annoncé dans les médias qui officialisaient cette retraite en mentionnant le fait qu'elles étaient désormais considérées comme des adultes. Malgré l'attachement des auditeurs pour certaines de ces jeunes artistes, il y avait une volonté de conserver dans la définition du terme shôjo kashu l'apparence juvénile des interprètes, cette «innocence» qu'on leur attribuait depuis les années 1920 dans la littérature de jeunesse. Le point de vue ainsi porté sur les enfants chanteurs entretenait une fascination pour ces jeunes prodiges et opérait une distanciation très forte entre la culture enfantine et la culture adulte. L'âge d'or des shôjo kashu se situant à partir de 1930 et pendant la guerre, leurs représentations étaient bien plus soumises à la vision conservatrice de ces années-là que celles, plus sexualisées, qui figuraient dans la presse et les magazines de la décennie précédente. Par ailleurs, certaines ont eu un rôle crucial dans la participation à l'effort de guerre. C'est le cas de Kawada Masako (1934-2006) qui a chanté à la radio pendant le conflit mondial, puis au lendemain de la guerre a encouragé la population japonaise au rythme des mélodies enjouées qu'elle interprétait, devenant une véritable idole de son temps.

On constate que ces shôjo kashu représentent une vision fantasmée de l'enfance ingénue tout en proposant un modèle pour les adolescentes. Il n'était aucunement fait mention de la sexualité qui restait du ressort de la vie adulte. La distinction entre l'enfant et l'adulte était marquée symboliquement par l'annonce publique de la fin de leur carrière en tant que shôjo kashu. Kawada Masako affirma ainsi à la radio, lors d'une émission spéciale de la NHK lui étant consacrée en 1947 et alors âgée de 13 ans: "Comme je suis entrée à l'école pour filles ce printemps et afin d'étudier cette fois-ci la musique des adultes, j'ai décidé de me séparer de mes précieux, précieux [sic] dôyô.». En outre, leurs activités musicales pendant la période militariste et dans l'immédiat après-guerre devaient répondre à un besoin social, culturel ou psychologique qui ne pouvait visiblement être tenu que par des enfants «exceptionnels». En effet, si les 
répertoires chantés par les shôjo kashu traitaient pudiquement de sujets associés à l'enfance ou au patriotisme, l'idéal d'innocence qu'elles représentaient fut exploité à des fins commerciales. En devenant un objet d'adoration de la population, les shôjo kashu avaient un statut de star éphémère qui restait avant tout attaché à leur répertoire de chants pour enfants. Or, l'ambiguïté entretenue depuis 1920 sur la figure de la shôjo à la fois juvénile et sensuelle atteint un autre niveau avec l'arrivée de Misora Hibari sur la scène musicale. Nous verrons ci-après les caractéristiques de cette enfant star à mi-chemin entre la shôjo kashu et l'aidoru.

\section{La fabrique du corps sacré : Misora Hibari (1937-1989) et son héritage}

\section{De l'enfant chanteuse à la vedette de cinéma}

19 Misora Hibari naît Katô Kazue en 1937, huit ans avant la capitulation du Japon et la fin de la Seconde Guerre mondiale. Grande amatrice de chant, qu'elle avait appris auprès de sa mère, elle donna sa première représentation publique à l'âge de neuf ans, dans un théâtre de Yokohama. En 1948, la jeune Kazue rencontra Taoka Kazuo, homme d'affaires et parrain du groupe de yakuza Yamaguchi-gumi, qui fut un important soutien durant toute sa carrière. Mais ce fut la rencontre avec Kawada Haruhisa, le chanteur et comédien de vaudeville le plus célèbre de l'époque, qui permit à celle qui prit désormais le nom de scène Misora Hibari d'évoluer dans le monde du spectacle. Trois ans plus tard, elle fit ses débuts au cinéma en interprétant le premier rôle d'une comédie musicale de la Shôchiku, Nodo jiman kyô jidai (1949), puis dans le film Shin tôkyô ondo bikkuri gonin otoko (1949), avant de signer un contrat chez Nippon Columbia. Reconnue aussi bien pour ses talents de comédienne que de chanteuse, Misora diversifia ses compétences et gagna une grande popularité au Japon. Jusqu'à sa mort prématurée à l'âge de 52 ans, elle enregistra 1931 chansons, battit des records de vente avec ses disques, joua dans 170 films et 4600 pièces de théatre et fit 80 millions d'entrées à ses concerts ${ }^{27}$. Aujourd'hui encore, Misora Hibari est considérée par la population japonaise comme une icône de la musique populaire, comme l'atteste la récente émission de la NHK du 29 septembre 2019 qui lui a été consacrée.

Dès le début de sa carrière, Misora Hibari se distingua des jeunes chanteuses par ses qualités vocales et, plus particulièrement, par une attitude scénique extrêmement mature. Un vibrato large, une maîtrise des registres graves et des mélismes caractéristiques de la chanson populaire des adultes, une interprétation très juste du boogie-woogie chanté et un déhanchement au rythme de la mélodie... tous ces éléments inattendus créant un contraste frappant avec sa physionomie enfantine (elle avait alors douze ans), contribuant à la placer à part des shôjo kashu qui l'avaient précédée.

21 Comme nous l'avons vu, les chansons pour enfants dans l'après-guerre se divisaient en dôyô, considérés comme porteurs de qualités artistiques, et rekôdo dôyô, plutôt associés aux musiques commerciales et de masse. La performance vocale de Misora était plus adaptée aux chansons populaires des adultes car elle possédait les mêmes caractéristiques que les artistes de cette catégorie. Grâce aux rencontres avec Taoka et Kawada, et ayant ce dernier pour maître de chant, Misora vit sa carrière véritablement propulsée. Guidée par ces deux hommes d'affaires, Misora obtint rapidement quelques 
rôles dans des films, où elle révéla aussi son talent vocal au public en interprétant les chansons-titres ${ }^{28}$.

Parmi les nombreuses chansons en vogue de l'époque, ses reprises des œuvres de Kasagi Shizuko (1914-1985) ont déclenché une controverse. Kasagi Shizuko était la vedette de la troupe de Kawada et une chanteuse star de l'époque que l'on appelait « la reine du boogie-woogie ». Le succès que Kasagi connut à l'époque s'explique en partie par la morosité ambiante qui sclérosait le Japon de l'immédiat après-guerre. La société demeurait traumatisée par les bombardements aériens qui avaient détruit la plupart des grandes villes tandis que les problèmes de chômage et de logement s'exacerbaient. Les Américains prirent le commandement politique et économique du pays et les Japonais, qui durent non seulement accepter la défaite mais aussi subir l'occupation américaine, appréciaient alors grandement les chansons aux propensions émancipatrices. Cette effervescence peut être perçue comme un naïf élan d'enthousiasme à l'idée d'une liberté et d'une paix retrouvées, qui masquerait dans le même temps un sentiment d'angoisse général à l'égard de l'avenir ${ }^{29}$. La popularité de Kasagi fut ébranlée néanmoins par l'apparition de la jeune chanteuse de Yokohama. En effet, malgré les styles et les contenus des chansons de Kasagi, majoritairement destinés aux adultes, la jeune Misora sut parfaitement les interpréter. Peu à peu, Misora remporta la place de vedette jadis occupée par Kasagi.

\section{L'image équivoque de la femme dans ses chansons}

La représentation de la femme dans les chansons de Misora, qui ne correspondait guère à l'image de la jeune chanteuse à peine âgée d'une douzaine d'années, suscita un débat dans la société japonaise. Si les œuvres chantées par la jeune Misora traitaient de divers sujets, certaines, notamment celles qui décrivaient une relation amoureuse, contenaient des expressions explicites et sensuelles. C'est le cas par exemple dans le dernier couplet de sa deuxième chanson, intitulée Kanashiki kuchibue ("Sifflotement de chagrin ») (1949), qui était également la chanson principale du film du même titre. Elle y interprétait le rôle d'une jeune orpheline, Tanaka Mitsuko, qui avait été séparée de son frère, Kenzô, pendant la guerre. L'histoire s'articule autour du personnage de Kenzô qui cherche désespérément sa sœur.

Okano hoteru no akai hi mo

Mune no akari mo kieru koro

Minato kosame ga furu yô ni

Fushi mo kanashii kuchibue ga

Koi no machikado roji no hosomichi

Nagare iku

Itsuka mata au yubikiri de

Warainagara ni wakaretaga

Shiroi koyubi no itoshi-sa ga

Wasure rarenai sabishisa o

Uta ni utatte inoru kokoro no

Ijirashi-sa

Yoru no gurasu no sake yorimo

Moyuru beni.iro irosaeta

Koi no hana yue kuchizukete

Kimi ni sasageta bara no hana

Dora no hibiki ni yurete

Kanashiya yume to chiru 
De même que les lumières de l'hôtel sur la colline,

La flamme de mon cœur s'est éteinte,

Comme la bruine qui tombe sur le port,

Le sifflotement à la triste mélodie

Glisse à travers le quartier de l'amour,

Et ses ruelles étroites.

Nous nous sommes séparés en riant,

Croisant les doigts en nous promettant de nous revoir.

La finesse de ton petit doigt blanc,

Cette inoubliable tristesse,

Cette émotion que mon cœur prie et chante.

Le soir, devant un verre d'alcool

Dont le rouge éclatant se démarque

Après avoir donné un baiser à cette fleur amoureuse

La rose que je t'ai offerte

S'effeuille tristement avec mon rêve ${ }^{30}$

Kanashiki kuchibue décrit le chagrin d'amour d'un personnage (sans doute masculin ${ }^{31}$ ), qui s'est séparé d'une personne avec regret. La structure de la langue japonaise, qui fonctionne très souvent sans sujet ni objet, offre ici de multiples interprétations. Ce troisième couplet est composé de propos particulièrement suggestifs. Le terme "sake " dans le premier vers, indiquant un alcool en général dans la langue japonaise, est qualifié de «rouge éclatant» (littéralement «flambant, brûlant») dans le second, et fait allusion à l'excitation et à l'ivresse. Dans le troisième vers, «cette fleur amoureuse " pourrait désigner à la fois une fleur réelle mais également le sentiment amoureux du personnage, et évoque par conséquent une scène particulièrement sensuelle.

Le fait que la jeune Misora ait été choisie pour interpréter cette chanson a eu un grand retentissement dans la population japonaise en raison de l'âge qu'elle avait lorsqu'elle l'a chantée dans le film éponyme. Certains firent l'éloge de son interprétation de "génie ${ }^{32}$ ", d'autres montrèrent de la désapprobation à l'égard de sa voix, décrite comme celle d'une "chanteuse de chansons d'amour entre deux-âges ", inappropriée pour une jeune fille car "enrouée » et laissant paraître "une convoitise douceamère $^{33}$ ». On observe par ailleurs que les scènes dans lesquelles Misora chante la montrent toujours entourée d'un groupe d'hommes adultes, qu'il s'agisse de musiciens ou de spectateurs, apparemment sous son charme. Si l'absence de contact physique rend ces scènes moins suggestives que ne peuvent l'être celles des films où Shirley Temple est assise sur les genoux des hommes ${ }^{34}$, elles révèlent néanmoins l'adoration et la fascination qu'exerçaient les shôjo kashu sur les adultes, avec une ambiguïté supplémentaire apportée par l'attitude mature de la jeune Misora.

26 Deborah Shamoon, spécialiste de la littérature japonaise moderne et des études de genre, souligne que l'effervescence relative à la jeune Misora de l'époque s'expliquerait en partie par « une attitude de nihilisme, de désespérance et de débauche ${ }^{35}$ » liée à la culture du kasutori, développée à la fin des années 1940. Selon Douglas Slaymaker, «le mot kasutori désigne littéralement l'alcool de mauvaise qualité et renvoie à ce qui a alimenté une grande partie de la production créative de l'époque, du striptease à la "littérature de la chair" ou nikutai bungaku, qui a démenti toute poursuite intellectuelle en faveur de l'expérience physique (et bien souvent sexuelle) ${ }^{36} »$. Pour sa part, John W. Dower signale que «la prostitution des adolescentes était répandue et même encouragée par le gouvernement : à l'arrivée des forces d'occupation, le gouvernement 
japonais a recruté des milliers de filles destinées à devenir des prostituées autorisées à l'intention des GI américains afin de pallier aux viols et aux agressions ${ }^{37}$ ».

27 Dans un tel environnement social post-guerre, de nombreuses artistes japonaises furent recrutées dans les cabarets des bases militaires américaines, à l'instar de Kasagi Shizuko. Ainsi, cette conjoncture sociale a permis à la jeune Misora, qui imitait parfaitement les chanteuses « débauchées ", d'obtenir une grande popularité.

28 Comme le souligne Michael Bourdaghs, ironiquement l'occupation américaine amena une notion de liberté aux femmes japonaises. À travers l'importation d'éléments de la culture populaire américaine tels que le boogie-woogie ou le jazz, représentés par la figure de Kasagi, la population féminine au Japon a pu jouir d'« un fantasme d'une consommation illimitée en tant que concrétisation de la libertée ${ }^{38} »$. En reprenant le concept d'« industrie culturelle» d'Adorno, Bourdaghs souligne l'idéologie véhiculée par ces cultures populaires en faisant l'éloge de la consommation comme symbole de liberté, adopté par la population japonaise d'après-guerre. Le chercheur américain estime d'autre part que le boogie-woogie a particulièrement servi à promouvoir l'émancipation corporelle chez les femmes : en suscitant l'envie, chez les spectateurs, de danser et en accentuant la sexualité des corps, les femmes se sont approprié une forme d'expression corporelle qui pouvait aller jusqu'à provoquer le désir sexuel. Ainsi, «nous trouvons une similitude entre la libéralisation de la sexualité féminine et la réglementation en temps de guerre" avec celle des chanteuses de blues afroaméricaines après $1865^{39}$.

\section{La fabrique de « l'authenticité japonaise »}

29 Les critiques sur le corps sexué de la jeune Misora ne purent être longtemps ignorées par Nippon Columbia, où la jeune chanteuse avait signé son contrat. C'était d'autant plus problématique que cette représentation suggérait non seulement la sexualité des femmes, mais faisait également allusion à l'occupation américaine. Shamoon relève que chez Misora, la suggestion d'une forme de libération sexuelle s'effaça à mesure qu'elle s'impliquait dans le monde cinématographique, étroitement lié à l'industrie musicale. Il est intéressant de voir que tout au long du film Kanashiki kuchibue, Misora répète seulement le deuxième couplet de la chanson. Celui-ci évoque le souvenir de la séparation des deux personnages, et leur promesse de se retrouver en croisant mutuellement les doigts ${ }^{40}$. La mise en scène de ce geste, souvent pratiqué entre les enfants, aurait servi à insister sur la relation fraternelle des deux protagonistes. Ainsi, la chanson semble moins narrer une romance adulte que mettre en avant l'histoire triste d'une jeune orpheline.

Selon Shamoon, l'image de Misora, autrefois liée à la sexualité à travers des chansons américaines, fut stratégiquement associée à l'innocence enfantine et aux valeurs familiales. Le rôle de Misora dans le film, qui suscita un sentiment de nostalgie chez les spectateurs, mit en avant son image candide, comme ce sera le cas pour d'autres jeunes chanteuses des années plus tard. L'image de la jeune fille luttant contre la précarité dans le contexte anxiogène d'après-guerre et sous l'occupation réussit en outre à revivifier un sentiment patriotique. L'accueil très favorable du public japonais de l'époque ${ }^{41}$, vis-à-vis de cette figure à la fois chaste et patriotique, détermina désormais l'image de la jeune Misora, du moins jusqu'à ce qu'elle atteigne l'âge adulte. Cela explique également pourquoi les paroles décrivent toujours une forme d'amour 
platonique, et pourquoi Misora fut souvent travestie en jeune garçon, comme pour réprimer toute manifestation de féminité suggérant une forme de liberté. Selon Shamoon, il s'agissait d'une stratégie de l'industrie musicale qui voulait diffuser une représentation des femmes comme étant dociles, innocentes, dévouées à la famille et à la population japonaise. Une telle stratégie persisterait dans le monde de la musique populaire japonaise contemporaine.

\section{Les conséquences sur la représentation actuelle d'un genre hypernormé}

\section{De l'ère des shôjo kashu à celle des aidoru : héritage, rupture, transformations}

31 Des années plus tard, cette représentation de la fillette, qui avait commencé à se féminiser de manière contrôlée avec la figure de Misora, se concrétisa comme une norme de la vedette féminine, notamment avec la démocratisation de la télévision et le développement de l'industrie du spectacle, soutenus par une forte croissance économique ${ }^{42}$.

32 Ainsi, conceptualisant la notion de "star» dans son analyse de l'industrie cinématographique, le sociologue français Edgar Morin distingue deux aspects constitutifs de ces vedettes: celui de "mythe» et celui de "produit ${ }^{43}$ ». La "star" serait donc en premier lieu une incarnation divine, au regard des grands attributs «mythiques » projetés sur sa personne par le public. Morin désigne alors le processus de starification comme une production propre au système capitaliste, les "stars " étant, dans la logique industrielle capitaliste, des objets de consommation dont la valeur commerciale est sublimée par l'association d'une image à la fois publique et privée. Les stars elles-mêmes participent à cette fétichisation et sont les parties prenantes d'un " phénomène pseudo-religieux structuré dans le système de production commerciale capitaliste ${ }^{44} »$. À partir de cette théorie, le sociologue et psychologue Inamasu Tatsuo met en évidence la transformation de la notion de "star » en celle $\mathrm{d}^{\prime}$ ' aidoru ${ }^{45}$ ». Selon lui, cette évolution s'appuie sur la mutation et le développement des médias, notamment par la démocratisation du petit écran. Autrement dit, si les stars étaient les vedettes du temps de l'économie cinématographique, les aidoru seraient celles de la télévision. Les stars sont une catégorie de produits commerciaux dont le charisme est porté et entretenu par le cinéma, un média qui nécessite que «l'on paye pour y accéder ». La distance physique existant entre les stars de cinéma et le public les consacre au rang d'étoiles, de figures lointaines et inaccessibles. La position de ce média "noble », du moins aux yeux des spectateurs, est basée sur la réalité d'un système d'échange économique. Or, à mesure que la télévision se démocratise, les stars diffusées sur le petit écran se rapprochent davantage du public. La télévision crée un " espace intime » à l'intérieur des ménages ${ }^{46}$.

33 Le terme aidoru émergea dans les années 1960 jusqu'à devenir central dans l'industrie musicale japonaise, qui produisit depuis cette époque jusqu'à aujourd'hui plusieurs centaines d'aidoru ${ }^{47}$. Patrick Galbraith souligne que l'illusion d'intimité créée par la télévision n'est pas exclusive à la société nippone, mais qu'elle est «sans doute plus prononcée au Japon ", du fait des "performances des aidoru et des célébrités, qui interviennent dans toutes les catégories d'émissions et sur toutes les plateformes 
médiatiques ${ }^{48}$ ». Grâce à cette création d'un espace intime, la télévision instaure une relation émotionnelle et affective entre acteurs et spectateurs, donnant davantage de corps aux aidoru. Les aidoru sont ainsi considérées comme un produit du système plutôt qu'un genre musical en soi, et ce pour deux raisons : tout d'abord, comme le souligne Galbraith, parce que la figure de l'aidoru est centrale à l'industrie musicale japonaise et domine sa production ${ }^{49}$. D'autre part, le style musical des aidoru évoluant sans cesse, il ne saurait relever d'un genre qui soit homogène.

34 Il n'est pas possible de traiter dans cet article, portant sur la genèse du caractère hyperféminisé de l'aidoru, de l'ensemble de l'évolution de l'aidoru jusqu'à nos jours, mais il est néanmoins intéressant de présenter quelques figures majeures, semblant hériter de la représentation de la vedette féminine des années précédentes. C'est le cas de Yamaguchi Momoe (1959-). Cette dernière, aujourd'hui considérée comme une des aidoru légendaires, fit ses débuts en 1973, suite à son passage dans l'émission télévisée Sutâ tanjô («L'éclosion des stars»), un programme conçu pour révéler de nouveaux talent ${ }^{50}$. Contrairement à Misora Hibari, la chanteuse fut jugée moins talentueuse et charismatique que les autres candidates de l'émission. Aku Yû, parolier et producteur de l'émission Sutâ tanjô, préférait néanmoins des jeunes filles capables d'être "plus proches de leur public ${ }^{11} »$. Ainsi, il mit en place deux critères de sélection: les candidates devaient être jeunes et jolies, mais aussi maladroites, voire naïves. Yamaguchi semblait parfaitement correspondre à ce profil. Si la jeune femme jouissait d'une spontanéité naturelle, elle portait également en elle quelque chose de sombre, stigmate d'un passé difficile et de sa relation tumultueuse avec ses parents ${ }^{52}$. La population japonaise fut fascinée par son aura mélancolique et attendrissante qui, en un sens, humanisait sa position de vedette, autrefois volontairement mise à distance du public et de la réalité.

35 Du point de vue de l'évolution de leur représentation, en dépit d'une différence notable du point de vue de leur technique vocale, Shamoon constate des points communs entre Yamaguchi et Misora. Comme cette dernière, Yamaguchi avait une voix relativement grave pour son âge en début de carrière (quatorze ans) et interprétait des chansons suggérant une figure de jeune femme présentant un caractère " $\operatorname{coquin}^{53}$ ». Mais audelà de cette similitude, le parcours de Yamaguchi s'apparente également à celui de Misora. Yamaguchi s'impliqua dans le milieu cinématographique dès le début de sa carrière de chanteuse, puis, tout comme pour Misora, son image sexualisée fut modifiée selon les rôles de jeunes filles « innocentes » et « pures » qu'elle endossa. Sept ans après ses débuts, elle mit fin à ses activités, refusant l'« image artificielle » qu'on lui imposait et qui ne la réduisait à " rien de plus qu'une poupé ${ }^{54}$ ». Nous pouvons dresser le même constat avec le duo féminin Pink Lady (1976-1981), qui s'attira également de nombreuses critiques avec ses chansons provocatrices et ses chorégraphies, jugées trop lascives et excentriques pour des aidoru. Pink Lady souffrit de son image de «femmes audacieuses », tandis que Yamaguchi devenait trop « mature » pour accepter d'afficher la naïveté affectée attendue des aidoru.

36 On observe ainsi, chez Misora Hibari et les autres chanteuses lui ayant succédé, une tendance contradictoire à «fétichiser et désavouer la sexualisation des jeunes filles $\operatorname{artistes}^{55}$ ». Celle-ci serait au fondement de l'hypersexualisation des aidoru actuelles aux tenues et aux poses suggestives qui adoptent une attitude infantile, rappelant les qualités traditionnellement associées aux jeunes filles depuis les shôjo kashu: la virginité, la fragilité et la docilité. 


\section{De l'image de « sauveuse » à celle « qui est à sauver »}

37 s'évertuant à progresser dans sa propre carrière, a encouragé la population japonaise $\mathrm{au}$ lendemain de la guerre. Cette figure de la jeune fille naïve mais courageuse est aujourd'hui fréquemment observée dans la stratégie commerciale des aidoru, ou ce que Galbraith nomme «le business des idoles". Néanmoins, si Misora a tenu le rôle de l'enfant courageuse et mature, porteuse d'espoir à l'égard de l'avenir, qui inspirait du courage et de l'énergie à une population qui endurait les conséquences d'une guerre destructrice, les aidoru évoluent en revanche dans un tout autre contexte. Elles apportent un sentiment de réconfort à une catégorie de fans particulière: majoritairement des hommes. L'image de « sauveuse » se trouve donc renversée, car la finalité des aidoru est de consoler leur audience dans une relation affective et maternante. Par ailleurs, cette thérapie se réalise dans un paradoxe: les fans ne se trouvent pas dans un système dans lequel ils n'auraient qu'un rôle de récepteur (comme cela était le cas avec les stars du cinéma) car eux-mêmes encouragent leurs vedettes. Galbraith explique ainsi : «[L]es fans japonais (par un soutien public actif et en devenant des «substituts » des stars) ont tendance à se concevoir comme des participants plutôt que comme de simples observateurs du discours des célébrités (West 2006) ${ }^{56}$ ». À travers cette participation imaginaire au monde des célébrités, les fans trouvent leur place sociale, et ils/elles seront consolé(e) $s^{57}$.

L'aidoru est ainsi placée dès le début de sa carrière dans une relation de dépendance à sa communauté de fans. Cette position s'explique sans doute par la représentation des femmes, dominante dans la culture populaire japonaise. Plusieurs travaux ont abordé ce sujet, notamment dans les domaines des mangas, des anime et des jeux vidéo ${ }^{58}$. Ces recherches soulignent à quel point les représentations féminines sont dominées par une figure combinant à la fois « désir de protection » et «fragilité ». Spécialiste de la littérature américaine, Fujimori Kayoko relève que la conception animiste de la féminité est toujours très ancrée dans la société japonaise ${ }^{59}$ : par sa capacité exclusive à porter un enfant, la femme est une incarnation de la nature en tant qu' « agent de la genèse ». Cette notion animiste essentialise les fonctions génitales - et donc sociales de la femme, qui est systématiquement envisagée comme une « mère ». Il est pertinent de noter que cette notion va de pair avec une autre représentation féminine omniprésente dans la culture populaire : l'image de la belle enfant guerrière ${ }^{60}$. Dans cet imaginaire, la mère se voit en effet souvent associée à une guerrière, protectrice de ses enfants. L'image de femmes adultes, indépendantes, autonomes et libérées de leurs obligations maternelles est donc ici clairement rejetée. Selon Fujimori, la puérilité et l'immaturité outrancières de ces représentations féminines renvoient à l'effroi des hommes vis-à-vis de l'autorité ou de l'autonomie des femmes, ainsi qu'à leur volonté de domination. Le succès des jeunes chanteuses est porteur d'une dimension misogyne : leur personnalité puérile, naïve, jouant à la fois sur le mythe d'une virginité éternelle et d'une forme de pureté immarcescible, les éloigne d'autant plus de la "dangereuse " réalité des femmes adultes dont la potentielle autonomie fait craindre des revendications égalitaires et une redéfinition des rôles sociaux. Les jeunes chanteuses, elles, ne sont pas dotées de cette capacité d'autonomie, et sont en cela " rassurantes » pour leur public masculin. 
39 Cette perception peut néanmoins être nuancée par une stratégie volontairement adoptée par les aidoru elles-mêmes pour évoluer dans une industrie très masculine, et qui s'apparenterait à l'un des processus sociaux observés chez les chanteuses de jazz par Marie Buscatto ${ }^{61}$. En effet, à la différence de celles qui les ont précédées, une "relativisation" de leur statut d'idole transparaît progressivement dans les performances des aidoru des années $1980^{62}$. Ainsi, en dépit de la «naïveté » ou de la " fragilité » supposées définir leur image publique, les aidoru des eighties sont d'une certaine manière parvenues, par leur conscience des attentes du public, à détourner les codes performatifs et genrés auxquels les soumettait leur statut de «starlettes de la chanson $^{63}$ ».

40 On comprend ainsi que, dans un premier temps, le vedettariat des aidoru reposait sur une admiration et un culte excessif des personnalités: les aidoru ne pouvant par essence être ancrées dans le réel, leur adoration dépassait les cadres rationnels communément admis. Une aidoru devait correspondre aux canons de beauté de l'époque, dans la continuité des stars talentueuses de l'ère du cinéma. Une rupture intervint toutefois dans l'image des aidoru à partir des années 1980, qui consistait à proposer des aidoru qui ne soient pas nécessairement charismatiques. Dans un environnement médiatique à la densité quantitativement accrue, puisque de plus en plus d'émissions télévisuelles et de publicités étaient retransmises, il fut désormais exigé des aidoru qu'elles étoffent leur panel de compétences et deviennent de véritables "amuseuses", des habituées des plateaux. Cette polyvalence allait de pair avec la commercialisation de produits musicaux dont la production s'accompagnait d'une performance artistique distinctive, réduisant bien souvent la musique à une fonction de pure marchandise. Selon Murayama Ryôichi, les aidoru féminines des années 1980 et des suivantes sont ainsi généralement caractérisées par leur virginité (shojosei), leur sens de la performance (pafômansusei) et leur absence d'originalité intrinsèque qui assure leur popularité auprès des masses (shominsei) ${ }^{64}$.

41 Enfin, il faut ajouter que les conditions de travail des aidoru sont sous le contrôle des jimusho, c'est-à-dire des agences chargées de gérer la promotion des artistes et qui contrôlent une grande partie de leurs activités artistiques et médiatiques, entre formation individuelle (chant, danse, media training), promotion de leur image, et commercialisation/marketing de leurs œuvres. Or, les travaux de Takeda ${ }^{65}$ et Kamioka ${ }^{66}$ relèvent que la majorité des aidoru exercent leurs activités dans des conditions de travail contraignantes : considérées comme « des éternelles stagiaires » (car la banalité et l'inexpérience se trouvent au fondement de leur image), les aidoru ont l'obligation morale de se conformer à l'image qui leur est attribuée et de répondre à toutes les propositions de travail, la plupart du temps très peu rémunérées ${ }^{67}$.

\section{Conclusion}

42 L'histoire de la construction de la figure de l'aidoru est édifiante en ce qu'elle révèle les questionnements et les conceptions portés sur la jeune fille dans la société japonaise. Alors qu'au début des années 1920, à l'âge d'or des mouvements artistiques et littéraires vouant un culte de "l'enfant pur ", toutes allusions à la sexualité ou même aux relations amoureuses étaient écartées de la production musicale et de la représentation des shôjo kashu, au fur et à mesure que se développe le concept de shôjo, la frontière entre fillette et jeune fille s'amincit pour fusionner en une entité aux 
comportements ambigus. À la fois objet de fascination des adolescentes et des adultes en tant qu'enfant prodige, mais aussi de fantasme autour de leur virginité éphémère, les shôjo kashu acquièrent le statut de vedette de l'industrie cinématographique à partir des années 1950. La figure de Misora Hibari représente parfaitement cette transition. Pour les chercheurs comme Inamasu, elle se distingue des aidoru d'aujourd'hui en termes de compétences et de positionnement, et elle a bien le statut d'enfant star tel qu'il désignait les shôjo kashu. Mais elle s'en détache également en franchissant la frontière qui avait été tracée dans les représentations et les répertoires propres aux artistes enfants et à ceux des adultes. Les aidoru, quant à elles, perdent peu à peu cette position de star inaccessible pour satisfaire à la demande d'une industrie musicale qui les place au centre d'une stratégie commerciale les obligeant à pratiquer un fan service distinct de leurs compétences et talents artistiques. La limite symbolique de l'âge a elle aussi disparu puisque des groupes d'aidoru comme les AKB48 comprennent des jeunes filles âgées de 13 à plus de 25 ans.

Dans cet article, nous sommes remontées à l'ère des shôjo kashu afin de mieux saisir les aspects naifs, infantiles, de la représentation des aidoru. Mais cela a également permis de révéler comment se trouvaient, dans la figure de la shôjo kashu, les prémices de la sexualisation de la jeune fille, une première forme d'émancipation de la figure de l'enfant, qui n'a pu se concrétiser en raison du conflit mondial. Elle réapparaît aprèsguerre, encouragée par les apports et l'industrie culturels promus par les États-Unis, mais rapidement étouffée comme nous l'avons vu chez Misora Hibari, car trop associée à une forme de libéralisation de la femme. L'aidoru des années 1970 doit correspondre à un juste équilibre : suggérer cette sexualité naissante et donc fortement encline aux fantasmes, mais ne pas s'affranchir de la vision rassurante traditionnellement associée à la femme. Si la carrière de Misora permet de comprendre de quelle manière s'est faite la transition entre shôjo kashu et aidoru, on peut s'interroger sur la question de son héritage. En septembre 2019, une émission spéciale de la NHK intitulée AI de yomigaeru Misora Hibari («Misora Hibari renaît grâce à l'intelligence artificielle»), diffusa une interprétation de la voix synthétisée de la chanteuse mise au point par Yamaha, à l'occasion du $30^{\mathrm{e}}$ anniversaire de sa mort. Les paroles de la chanson interprétée furent composées par Akimoto Yasushi, producteur des groupes d'aidoru japonaises Onyanko Club et AKB48, notamment. Au-delà des débats sur la médiatisation post-mortem et le problème moral posé par une production exploitant l'image et la voix d'un défunt, l'intérêt d'individus comme Akimoto pour Misora est une autre preuve de la filiation entre les shôjo kashu des années 1950 et les aidoru actuelles, et de l'influence des premières sur les secondes.

\section{BIBLIOGRAPHIE}

AKU Yû, Yume wo kutta otoko tachi - «sutâ tanjô » to kayôkyoku ôgon no nanajûnendai (« Ces hommes qui ont croqué leurs rêves à pleines dents : «Sutâ tanjô » et les années 1970, l'âge d'or du kayôkyoku »), Tôkyô, Bungei shunjû, 2007. 
AOYAGI Hiroshi, Islands of Eight Million Smiles: Idol Performance and Symbolic Production in Contemporary Japan, Cambridge, Harvard University Press, 2005.

AZAMI Toshio, Popurâ ongaku wa dare ga tsukuru no ka : ongaku sangyô no seijigaku (« Qui fabrique la musique populaire ? Sciences politiques de l'industrie musicale »), Tôkyô, Keisô Shobô, 2004.

BOURDAGHS Michael K., Sayonara Amerika, sayonara Nippon: a geopolitical prehistory of J-pop, New York, Columbia University Press, 2012.

FUJIMORI Kayoko, « Disney animêshon to feminizumu no juyô/senyû - Mulan ni okeru onna senshi no hyôshô wo megutte » («Les films d'animation de Disney et la réception/possession du féminisme - de la représentation des guerrières dans le film Mulan»), 1999 : http://www. aynrand2001japan.com/reports/report2_5.html, consulté 22 mars 2016.

GALBRAITH Patrick W. et KARLIN Jason G. (dir.), Idols and celebrity in Japanese media culture, Houndmills, Basingstoke, Hampshire, New York, Palgrave Macmillan, 2012.

HIGONNET Anne, Pictures of innocence: the history and crisis of ideal childhood, Thames and Hudson, 1998.

HOBSBAWM Éric, RANGER Terence (dir.), L'Invention de la tradition, Paris, Éditions Amsterdam, 2012. INAMASU Tatsuo, Aidoru kôgaku (« L’ingénierie des aidoru »), Tôkyô, Chikuma Shobô, 1989. INAMASU Tatsuo, « Introduction to Japanese Ideology », in Bulletin of Society for Changing Customs in Contemporary Japan, vol. 16, 2015, p. 32-41.

KATSUKI Takashi, « Aidoru » no yomikata : konran suru « katari » o tou [Une grille de lecture des aidoru : les enjeux de « discours » confusionnels], Tôkyô, Seikyûsha, 2014.

KоJIMA Tomiko, Nihon dôyô ongaku shi, Tôkyô, Daiichi shobô, 2004.

KUME Yoriko, Junchi sareru sekushuariti ; modanizumu ki zengo shôjo zasshi to kôtsû, in Japanese Literature vol. 58, $\mathrm{n}^{\circ}$ 11, 2009, p. 24-33.

LEVY Christine (éd.), Genre et modernité au Japon : la revue Seitô et la femme nouvelle, Rennes, Presses Univ. de Rennes (coll. « Archives du féminisme »), 2014.

МАКІмото Kusurô, Puroretaria dôyô no katsuyô ni kansuru oboegaki - jidô no shidôsha hogosha tachi ni, Tôkyô, Kôgyokudô shoten, 1930.

мАКІмото Kusurô, Akai hata, Tôkyô, Kôgyokudô shoten, 1930.

MATSUNAGA Goichi, Nihon no komori uta, Tôkyô, Kadokawa bunko, 1984.

MICHEL-LESNE Claude, «La question de la mixité dans le théâtre Takarazuka : jeux d'ombre et de lumière », Cipango [En ligne], 20/0|/2013, mis en ligne le 15 avril 2015, consulté le 20 janvier 2020. URL : http://journals.openedition.org/cipango/1944 ; DOI : https://doi.org/10.4000/cipango.1944 Misora Hibari Muséum : https://www.misorahibari.jp/, consulté le 21 novembre 2019. MOROI Katsuhide, «A Pop Star is Adapting to the Times », in Dôshisha daigaku seikatsu kagaku, vol. 47, 2013, p. 38-42.

MURAYAMA Ryôichi, AKB 48 ga hitto shita itsutsu no himitsu : Burêku genshô wo mâketingu senryaku kara saguru [Les cinq secrets du succès d'AKB48 : une exploration des phénomènes de percée sous l'angle de la stratégie marketing], Tôkyô, Kadokawa shoten, 2011.

o'CONNOR Jane Catherine, The Cultural Significance of the Child Star, Routledge, 2010, (version ebook). OGAWA Hiroshi, Ongaku suru shakai, Keisô shobô, 1988. 
PAINTER Andrew A., « Japanese Daytime Television, Popular Culture, and Ideology », Journal of Japanese Studies, vol. 19, n², 1993, p. 197-234.

SAITô Tamaki, Sentô bishôjo no seishin bunseki (« Psychanalyse des belles enfants guerrières »), Tôkyô, Chikuma shobô, 2006.

SAITô Minako et al., Kôittenron (« La théorie de la seule femme dans le cercle »), Tôkyô, Chikuma Shobô, 2001.

SAKOGUCHI Sanae, Bugi no joô Kasagi Shizuko - kokoro zukizuki wakuwaku aa shindo [Kasagi Shizuko, la reine du boogie-woogie - tantôt blessée, tantôt folâtre, que cela me fatigue !], Gendai shokan, 2010.

SASAYAMA Keisuke, Maboroshi no kindai aidoru-shi : Meiji, Taishô, Shôwa no taishû geinô seisuiki, Tôkyô, Sairyûsha, 2014.

SHAMOON Deborah, « Misora Hibari and the Girl Star in Postwar Japanese Cinema ", Signs: Journal of Women in Culture and Society, vol. 35, p. 131-155.

sUZUKI Miekichi, Akai tori, Préface, nº 1, Tôkyô, 1918.

TAKEDA Keiko, « Raibu aidoru, kyôdôtai, fan bunka - aidoru no rôdô to fan komyuniti », in Tanaka Toko (dir.) Dekigoto kara manabu karuchuraru stadîzu, Nakanishiya shuppan, 2017, p. 117-133.

TANSMAn Alan, « Mournful Tears and Sake: The Poswar Myth of Misora Hibari », Whitter T. John (dir.), Contemporary Japan and Popular Culture, Richmond Surrey, Cuzon Press, 1996, p. 103-133. YAMAZUMI Masami, Kodomo no uta wo kataru, shôka to dôyô, Tôkyô, Iwanami shoten, Japon, 1994.

\section{NOTES}

1. Nous optons pour la transcription aidoru afin de désigner spécifiquement les musicien(ne)s japonais(es) relevant de cette catégorie d'artistes.

2. Dans ce film, le personnage incarné par Johnny Hallyday est considéré comme un aidoru, à savoir un chanteur célèbre, tout comme dans la réalité.

3. AOYAGI Hiroshi, Islands of Eight Million Smiles: Idol Performance and Symbolic Production in Contemporary Japan, Cambridge, Harvard University Press, 2005, p. 4-5.

4. INAMASU Tatsuo, "Introduction to Japanese Idology ", in Bulletin of Society for Changing Customs in Contemporary Japan, vol. 16, 2015, p. 33.

5. Le Japon est régulièrement pointé du doigt en raison de sa vision conservatrice de la position de la femme dans la sphère professionnelle, les médias et le cercle familial. En 2020, il est classé $121^{\mathrm{e}}$ sur 153 pays (la France est $15^{\mathrm{e}}$ ) dans le rapport annuel du Forum économique mondial (WEF) sur les inégalités entre hommes et femmes.

6. Les premiers chants scolaires furent ainsi conçus sur des mélodies variées dont les paroles avaient été remplacées par des textes japonais: il pouvait s'agir d'airs d'opéra, de chants populaires tels que le fameux Auld sang lyne, ou bien encore de cantiques et d'hymnes religieux.

7. Cela favorisa l'apparition des volontés de renouvellement et de changement de la culture enfantine dans divers domaines: le peintre de yôga ("peinture occidentale ») Yamamoto Kanae révolutionna ainsi l'éducation artistique des enfants, jusque-là centrée sur la reproduction fidèle de modèles, en organisant notamment en 1919 une exposition de dessins libres des enfants jidô jiŷu-ga qui s'étendit au mouvement du même nom. Le dramaturge Tsubouchi Shôyô développa quant à lui le jidô geki, ou "théâtre pour enfants ». On les décrit de façon générale comme des 
«mouvements éducatifs artistiques ». YAMAZUMI Masami, Kodomo no uta o kataru, shôka to dôyô, Tôkyô, Iwanami shoten, Japon, 1994, p. 111.

8. SUZUKI Miekichi, Akai tori, préface, $\mathrm{n}^{\circ} 1$, Tôkyô, 1918.

9. Ayant suivi des études de littérature anglaise, il avait en effet constaté l'effort important réalisé dans les pays européens au cours $\mathrm{du} \mathrm{XIX}^{\mathrm{e}}$ siècle par les sociétés savantes comme les associations d'amateurs pour la collecte et la centralisation des contes et des comptines populaires.

10. D'après la musicologue Kojima Tomiko, les compositeurs de l'époque ont ignoré les caractéristiques mélodiques des comptines japonaises, qui possèdent un lien organique avec la langue parlée, et produit un répertoire hybride ressenti comme un artifice en harmonisant des mélodies pensées selon une échelle pentatonique. Voir коJıмA Tomiko, Nihon dôyô ongaku shi, Tôkyô, Daiichi shobô, 2004.

11. HOBSBAWm Éric et Terence RANGER (dir.), L'Invention de la tradition, Paris, Éditions Amsterdam, 2012, p. 31.

12. Ce discours universaliste fut d'ailleurs critiqué plus tard par des individus comme l'auteur de littérature de jeunesse Makimoto Kusurô, qui reprochait aux dôyô issus des revues comme Akai tori de ne s'adresser qu'aux enfants des classes bourgeoises et d'imposer un modèle d'insouciance stéréotypé qui ne concernait pas les enfants des couches les plus populaires. МАКімото Kusurô, Puroretaria dôyô no katsuyô ni kansuru oboegaki - jidô no shidôsha hogosha tachi ni, Kôgyokudô shoten, 1930, et МАКімото Kusurô, Akai hata, 1930.

13. HIGONNET Anne, Pictures of innocence: the history and crisis of ideal childhood, Thames and Hudson, 1998.

14. Ainsi, les berceuses, appelées en japonais komori uta (« chansons de gardes d'enfants »), et qui en sont un exemple caractéristique, avaient été écartées du répertoire enfantin et rattachées au min.yô, c'est-à-dire les chansons régionales des adultes. Étymologiquement, le nom de ces berceuses vient du terme komori hôkô, une pratique courante jusque dans les années trente chez les familles bourgeoises de faire appel à des gardes d'enfants, âgées entre sept et quinze ans et appelées moriko ou plus familièrement nêya. Beaucoup de ces chansons, destinées à endormir l'enfant dont ces gardes avaient la charge, décrivaient le quotidien de labeur de ces filles parfois très jeunes, qui étaient séparées de leurs familles (souvent par souci d'économiser une bouche à nourrir) et restaient enfermées au service d'inconnus. Bien souvent, ces jeunes filles n'achevaient pas leur scolarité et entraient en service comme bonnes dans de riches demeures, ou bien devenaient ouvrières. On retrouve des images de ces petites filles portant sur le dos des nourrissons et enfants en bas-âge jusque dans les années d'avant-guerre.

15. Nous pensons notamment au concours de la NHK Nodo jiman, qui existe depuis 1946 et qui fut d'abord un programme musical radiodiffusé, intitulé Nodo jiman shirôto ongakukai.

16. L'un des compositeurs les plus représentatifs de ce phénomène est Nakayama Shinpei. Le succès rencontré par ce dernier fut tel que les années vingt sont communément qualifiées d'années Shinpei bushi, soit les années « des airs de Shinpei » que l'on pouvait entendre partout. Formant un trio très productif avec les poètes Kitahara Hakushû et Saijô Yaso, il composa des dôyô qui pouvaient prétendre au statut de « tube ».

17. Par exemple Shôjo no tomo «L'ami des jeunes filles » (1908-1955), Shôjo kurabu « Le club des filles » (1923-1962) ou encore Shôjo gahô « La revue illustrée pour filles » (1912-1942).

18. o'CONNOR Jane Catherine, The Cultural Significance of the Child Star, Routledge, 2010, p. 9 (version ebook).

19. La première revue pour jeunes filles, Shôjo kai («Le monde des filles »), a été créée en 1902.

20. Kôtô jogakkô rei en japonais.

21. Propos du rédacteur en chef de Shôjo sekai, Numata Tôji. KUME Yoriko, Junchi sareru sekushuariti ; modanizumu ki zengo shôjo zasshi to kôtsû, in Japanese Literature 58(11), 2009, p. 25. 
22. Une représentation encore d'actualité dans les shôjo manga.

23. Voir LEVY Christine (éd.), Genre et modernité au Japon : la revue Seitô et la femme nouvelle, Rennes, Presses Univ. de Rennes (coll. « Archives du féminisme »), 2014.

24. KUME, Junchi sareru sekushuariti, p. 29.

25. Le Takarazuka est une compagnie de théâtre japonaise du genre revue, créée en 1914 dans la région du Kansai et uniquement composée de femmes non mariées. Les artistes, à la fois chanteuses, danseuses et comédiennes, se spécialisent dans l'interprétation des rôles masculins (otokoyaku), ou des rôles féminins (musumeyaku) dans des romances mélodramatiques essentiellement adressées à un public adolescent et féminin. MICHEL-LESNE Claude, « La question de la mixité dans le théâtre Takarazuka : jeux d'ombre et de lumière ", Cipango [En ligne], 20/0|/ 2013, mis en ligne le 15 avril 2015, consulté le 20 janvier 2020. URL: http:// journals.openedition.org/cipango/1944; DOI : https://doi.org/10.4000/cipango.1944

26. KUME, Junchi sareru sekushuariti, p. 27.

27. Données issues du site du Musée Misora Hibari : https://www.misorahibari.jp/, consulté le 21 novembre 2019. La résidence de Misora Hibari, aujourd'hui transformée en musée, conserve la plupart des archives de sa vie professionnelle et personnelle.

28. Il est à souligner qu'à l'époque la scène cinématographique occupait une place importante dans la stratégie de promotion des œuvres par l'industrie musicale japonaise. AzAMI Toshio, Popurâ ongaku wa dare ga tsukuru no ka: ongaku sangyô no seijigaku, Tôkyô, Keisô Shobô, 2004, p. 104-106.

29. SAKOGUCHI Sanae, Bugi no joô Kasagi Shizuko - kokoro zukizuki wakuwaku aa shindo, Gendai shokan, 2010, p. 78-88.

30. MISORA Hibari, Kanashiki Kuchibue, Nippon Columbia, 1949.

31. Le pronom kimi désigne la deuxième personne du singulier, et était généralement employé à l'époque par la gent masculine.

32. TANSMAn Alan, « Mournful Tears and Sake: The Postwar Myth of Misora Hibari » in WHITTER T. John (dir.), Contemporary Japan and Popular Culture, Richmond Surrey, Cuzon Press, 1996, p. 125.

33. SHAMOON Deborah, "Misora Hibari and the Girl Star in Postwar Japanese Cinema ", Signs: Journal of Women in Culture and Society, vol. 35, p. 138.

34. O'CONNOR, The Cultural Significance of the Child Star, p. 28.

35. SHAMOON, « Misora Hibari and the Girl Star in Postwar Japanese Cinema », p. 135.

36. SLAYMAKER Douglas N. The Body in Postwar Japanese Fiction, Londres, Routledge, 2004, p. 43-70.

37. DOWER John. W., Embracing Defeat: Japan in the Wake of World War II, New York/London, W. W. Norton \& Company, 1999, p. 127.

38. BOURDAGHS Michael K., Sayonara Amerika, sayonara Nippon: a geopolitical prehistory of J-pop, New York, Columbia University Press, coll. « Asia perspectives: history, society, and culture », 2012, p. 33.

39. Ibid., p. 35.

40. Appelé yubikiri, le geste de croiser mutuellement les auriculaires est fréquemment pratiqué au Japon entre deux personnes pour sceller une promesse.

41. TANSMAN, " Mournful Tears and Sake: The Postwar Myth of Misora Hibari », p. 120-121.

42. Plus de la moitié des ménages japonais possédaient une télévision en 1960. Lorsque les Jeux Olympiques se tinrent à Tôkyô quatre années plus tard, le taux de possession de cet équipement atteignait déjà $87.8 \%$. SASAYAMA Keisuke, Maboroshi no kindai aidoru-shi: Meiji, Taishô, Shôwa no taishû geinô seisuiki, Tôkyô, Sairyûsha, 2014, p. 9-10.

43. MORIN Edgar, Les Stars, Le Seuil, 1972, cité par Inamasu.

44. INAMASU Tatsuo, Aidoru kôgaku [L'ingénierie des aidoru], Tôkyô, Chikuma Shobô, 1989, p. 213.

45. INAMASU, « Introduction to Japanese Idology », 2015, p. 33-34. 
46. PAINTER Andrew A., «Japanese Daytime Television, Popular Culture, and Ideology », in TREAT John Whittier (dir.), Contemporary Japan and Popular Culture, University of Hawai'i Press, 1996, p. 197-234.

47. MOROI Katsuhide, "A Pop Star is Adapting to the Times ", in Dôshisha daigaku seikatsu kagaku, vol. 47, 2013, p. 38-42

48. GALBRAITH Patrick W. et KARLIN Jason G. (dir.), Idols and Celebrity in Japanese Media Culture, New York, Palgrave Macmillan, 2012, p. 9.

49. Ibid., p. 3.

50. OGAWA Hiroshi, Ongaku suru shakai, Keisô shobô, 1988, p. 127.

51. AKU Yû, Yume wo kutta otoko tachi - "sutâ tanjô " to kayôkyoku ôgon no nanajûnendai, Tôkyô, Bungei shunjû, 2007, p. 28.

52. Ibid.

53. Par exemple, dans la chanson intitulée Fruit vert (1973), on constate un passage assez provocateur: «si vous le désirez, je suis prête à accepter tout ce que vous voulez de moi ". SHAMOON, « Misora Hibari and the Girl Star in Postwar Japanese Cinema », p. 150.

54. YAMAGUCHI Momoe, Aoi toki (« Les temps verts »), Shûeisha, 1981, cité par Aku.

55. SHAMOON, " Misora Hibari and the Girl Star in Postwar Japanese Cinema », p. 153.

56. GALBRAITH et KARLIN, Idols and Celebrity in Japanese Media Culture, p. 57-58.

57. À ce sujet, on observe des similitudes entre les chercheurs qui étudient les communautés de fans des sociétés occidentales et japonaises. Ainsi, Gray, Sandvoss \& Harrington, relèvent, dans les études menées sur les fans, une tendance à voir les comportements admirateurs comme un phénomène actif contre l'autorité et la classe dominante.

58. Voir entre autres SAITo Tamaki, Sentô bishôjo no seishin bunseki, Tôkyô, Chikuma shobô, 2006, ou SAITô Minako et al., Kôittenron, Tôkyô, Chikuma Shobô, 2001.

59. FUJIMORI Kayoko, «Disney animêshon to feminizumu no juyô/senyû - Mulan ni okeru onna senshi no hyôshô wo megutte ", 1999: http://www. aynrand2001japan.com/reports/ report2_5.html, consulté 22 mars 2019.

60. Certaines héroïnes des films d'animation de Miyazaki Hayao en sont emblématiques.

61. BUSCATTO Marie, Femmes du jazz. Musicalités, féminités, marginalités, Paris, CNRS Édition, 2007.

62. OGAWA, Ongaku suru shakai, p. 40.

63. C'est le cas de l'aidoru Matsuda Seiko qui, bien qu'à l'origine du terme burikko, dérivé de l'expression kawaiiko-buru/kawaiiko no furi wo suru, c'est-à-dire : «faire semblant d'être mignonne et faible", se jouait des codes et des normes sociales en adoptant ce comportement tout en assumant son statut de mère, et ce tout au long de sa carrière. Il s'agissait d'un choix artistique conscient, et non subi, puisque l'artiste se conçoit ici délibérément comme un dispositif de divertissement.

64. MURAYAMA Ryôichi, AKB 48 ga hitto shita itsutsu no himitsu : Burêku genshô wo mâketingu senryaku kara saguru, Tôkyô, Kadokawa shoten, 2011, p. 130-136.

65. TAKEDA Keiko, «Raibu aidoru, kyôdôtai, fan bunka - aidoru no rôdô to fan komyuniti ", in TANAKA Toko (dir.) Dekigoto kara manabu karuchuraru stadîzu, Nakanishiya shuppan, 2017, p. 117-133.

66. КАМІоКА Mana, Yokuatsu sareta pafômâ no sôzôsei - aidoru wo jirei ni -, intervention dans le cadre du Colloque de la Société de Sociologie du Japon qui s'est tenue le 6 octobre 2019 à Tôkyô.

67. KATSUKI Takashi, «Aidoru » no yomikata : konran suru « katari » o tou, Tôkyô, Seikyûsha, 2014. 


\section{RÉSUMÉS}

Le phénomène des aidoru, ces jeunes vedettes féminines à la fois chanteuses, danseuses et actrices, souvent issues de groupes de pop japonaise fabriqués de toutes pièces par une puissante industrie musicale, s'est grandement développé à la fin des années 1960. La forte médiatisation de ces jeunes artistes les soumet à des exigences importantes, en particulier physiques et morales : elles doivent adopter des tenues et des comportements pour satisfaire et fidéliser leurs fans. Mais leur représentation d'adolescentes modèles aux caractéristiques physiques et aux attitudes hyperféminisées peut troubler, tant elle joue à la fois sur un mode de séduction et d'allusions sexuelles, et sur une apparence volontairement enfantine et immature. Leur carrière et leurs salaires étant déterminés par leur notoriété, cette dernière pouvant rapidement être mise à mal par un scandale touchant à leur vie privée, les aidoru évoluent dans une relation avec leur public qui s'apparente à un dispositif de voyeurisme et de fan service.

Cette figure de la chanteuse ou actrice adolescente à succès s'observe déjà avant-guerre, avec le phénomène des shôjo kashu ("fillettes chanteuses »). Elles incarnent alors la pureté et l'innocence de l'enfance et sont bien souvent cantonnées à des répertoires et des rôles qui valorisent ces qualités. Or, dans les années 1950, des artistes comme Misora Hibari semblent s'éloigner peu à peu de cette vision et offrir une image jouant sur une ambiguïté séductrice s'incarnant dans un corps d'enfant. Dans cet article, nous reviendrons sur les contextes historiques et culturels dans lesquels ont évolué shôjo kashu et aidoru, afin de mieux comprendre ce qui constitue un phénomène majeur dans l'industrie musicale japonaise.

The phenomenon of the aidoru, young female stars that are singers, dancers and actresses, and often come from Japanese pop groups made from scratch by a powerful music industry, developed greatly in the late 1960s. The high media coverage of these young artists puts them under important physical and moral demands: they must adopt outfits and behaviors to satisfy and retain their fans. But their portrayal of model adolescents with physical characteristics and hyperfeminized attitudes can be disturbing, as it plays both on seduction and sexual allusions, and on a deliberately childish and immature appearance. Their careers and salaries are determined by their notoriety, which can quickly be undermined by a scandal affecting their privacy, and the aidoru evolve in a relationship with their public that resembles a device of voyeurism and fan service.

This figure of the successful teenage singer or actress has been present since before the war, with the phenomenon of shôjo kashu ("girl singers"). They embody the purity and innocence of childhood and are often confined to repertoires and roles that value these qualities. However, in the 1950s, artists like Misora Hibari seemed to gradually move away from this vision and offer an image playing on a seductive ambiguity embodied in a child's body. In this article, we will return to the historical and cultural contexts in which shôjo kashu and aidoru evolved, in order to better understand a major phenomenon in the Japanese music industry.

\section{INDEX}

Mots-clés : Aidoru, idole, musique populaire japonaise, Misora Hibari, shôjo kashu (« fillette chanteuse »), dôyô (" chant pour enfants »), vedette, genre, enfant star, industrie musicale japonaise

Keywords : Aidoru, idol, Japanese popular music, Misora Hibari, shojo kashu (girl singers), doyo (children songs), vedette, gender, child star, japanese musical industry 


\section{AUTEURS}

\section{CHIHARU CHÛJÔ}

Docteure en études du Japon et maître de langue de japonais à l'Institut national des langues et civilisations orientales, Chiharu Chûjô a soutenu en 2018 sa thèse sur les musiciennes japonaises engagées des années 1970 à aujourd'hui. Ses recherches actuelles se focalisent sur la condition du travail des femmes dans la scène de la musique populaire japonaise.

\section{CLARA WARTELLE-SAKAMOTO}

Clara Wartelle-Sakamoto est docteure de l'Institut national des langues et civilisations orientales en Histoire, Sociétés et Civilisations et l'auteure d'une thèse intitulée « Les chants pour enfants au Japon au début du $\mathrm{xx}^{\mathrm{e}}$ siècle $\mathrm{e}$ de la réception à l'affirmation d'une identité musicale ». Actuellement maître de langue de japonais à l'Inalco et chercheuse associée à la Bibliothèque Nationale de France, ses thématiques de recherche s'articulent autour de l'histoire de la musique et de son enseignement, de la littérature de jeunesse et du folklore enfantin au Japon. 